\title{
Simulation of lightning surges on tower transmission using PSCAD/EMTDC: a comparative study
}

\begin{abstract}
This paper describes the analytical and the experimental responses of the surges strike on the transmission line towers. A new method of calculating transmission tower surge response has been proposed. It has been found that the tower surge response calculated by the proposed method has a close agreement with the measured tower surge response obtained from scale model and field tests. Without the use of simulation program, this topic might be difficult to understand. PSCAD/EMTDC has been selected as the software used to generate the appropriate data needed to graphically demonstrate this phenomenon.
\end{abstract}

Keyword: Tower transmission; PSCAD/EMTDC; Tower surge response 